$J J M L L$

\title{
The Pragmatic Functions of Facebook Likes on Status Updates: Evidence from User Perceptions
}

\author{
Hady J. Hamdan* \\ Department of English Language and Literature, The University of Jordan, Jordan
}

Received on: $28-5-2020$

Accepted on: 8-12-2020

\begin{abstract}
This paper examines the pragmatic functions of the like button when users interact with statusupdates on Facebook. To collect the data, the researcher asked a friend who happened to be a university professor to write a post on his Facebook account in which he requested his students, colleagues and friends to report to him in a comment when each of them tends to press the like button on a status and for what purpose. The total number of the collected comments is 218 . Analysis of the data reveals that in the Jordanian context, the like button is not solely used to show appreciation as originally envisaged by Facebook. Further, the findings indicate that the use of the like button has eventually developed as a graphic pragmatic marker with eight functions and illocutions ranging in purpose from showing unreserved approval and admiration of content to showing mockery of published content.
\end{abstract}

Keywords: Computer-Mediated Communication; Emojis, Gestures; Like; Pragmatic Functions.

\section{Introduction}

In this ever-changing world, many of yesterday's luxuries have changed to become today's necessities. In the same vein, having an account on Facebook, Twitter or any other social network which was once a luxury for many is now becoming increasingly imperative for anyone who wants to keep abreast of the latest news and be in touch with relatives, close friends, and even co-workers and colleagues. With over 2.5 billion monthly active users (Noyes, 2020), Facebook, definitely, is penetrating and becoming an integral part of our everyday lives. Put differently, "Facebook is not just a technology [anymore]. It is a mobile identity for people. Just as people cannot go without food, they probably cannot go without Facebook" (Stevenson, 2016). Linguistically, this role that Facebook plays as a medium for communication has motivated considerable research to examine several linguistic phenomena that occur within it as a means of computer-mediated communication (CMC). In this regard, one may draw attention to studies that focused on CMC across languages and cultures (Al-Sa'di \& Hamdan, 2005; Hamdan, 2012; Pérez-Sabater, 2012; Halim \& Maros, 2014; Dressler \& Dressler, 2016; Magwaro, Odhiambo \& Owala, 2018; Banikalef, 2019, Hamdan and Al-Salman, 2021, among others). However, one feature in Facebook which has not received thorough scholarly attention and is still awaiting further research is the like feature. Consequently, the study reported here aims to investigate only one aspect of this feature, viz.,

() 2021 JJMLL Publishers/Yarmouk University. All Rights Reserved,

${ }^{*}$ Doi: https://doi.org/ 10.47012/jjmll.13.4.4

*Corresponding Author: hady_hamdan@windowslive.com 
Hamdan

the pragmatic functions of the like button with a view to identifying when Facebook users press it and for what purposes.

Language is developing rapidly in a way that is hard to explain or imagine. Although the Facebook like button is commonly perceived as an internet equivalent of the real-time hand gesture 'thumbs up' to indicate approval and appreciation, this paper seeks to provide evidence that the actual use of this button is evolving beyond its initial function as a marker of appreciation and that it has eventually developed as a pragmatic marker with multiple illocutions and functions. However, before proceeding with this presentation and for readers' convenience, a brief account of CMC in general and emojis as forms of nonverbal CMC in particular is due. The brief will also touch on Facebook and the like button in addition to pragmatics and discourse markers.

\section{An Overview of CMC}

The mediums of communication among human beings have always received considerable attention from the different fields of linguistics due to their vital role in the survival and reproduction of humanity. Traditionally, the two main means of communication are spoken and written. The first method consists of a speaker/sender and a hearer/receiver engaged in an encode-decode model in which the speaker encodes his/her message through the use of pragmatics, syntax, speech sounds and lexical items to the hearer who decodes this message. The second method consists of a writer and a reader, also engaged in an encodedecode model in which the writer/sender expresses his/her ideas in writing through the use of cohesion, coherence and other textuality requirements, and the reader/receiver decodes the written text through visual reading. In addition to these two methods, a third method is used through the use of nonverbal gestures while dealing with deaf people and is referred to as sign language. However, the growing role of the Internet and the development of technology resulted in the introduction of a fourth medium of communication, a unique hybrid register (Al-Sa'di \& Hamdan, 2005) "which relies on a blend of features from both traditional modes of communication in addition to features of its own" (Hamdan, 2012, p. 144).

This new mode of communication, called CMC by some and electronic language by others, has been thoroughly discussed from different perspectives. While some examined the linguistic and textual features of CMC (Crystal, 2001; Segerstad, 2002; Al-Sa'di \& Hamdan, 2005; Denis, 2008; Hamdan, 2012, Hamdan and Al-Salman, 2021, among others), others attempted to investigate the commonalities and differences between this new mode of communication and previous modes such as writing and speaking (Crystal, 2001; Palfreyman \& Al-Khalil, 2003 and Denis, 2008).

In one of the earliest studies to investigate verbal communication represented through the written mode in CMC, Al-Sa'di and Hamdan (2005) delineate the linguistic and textual features of the English used on the Internet Relay Chat (IRC) channels and the Yahoo Messenger chat rooms. They describe sentence length and complexity, salient sentence classes, lexical properties, neologisms, taboos, and the extent to which cyber English conforms to general English. The findings of their study reveal that the majority of sentences in CMC are short and simple and that several word truncation methods are used. In addition, the study shows that there are no restrictions on the use of taboo words and that regular word formation methods are employed to make cyber words such as derivation, coinage and acronymization. 


\section{The Pragmatic Functions of Facebook Likes on Status Updates: \\ Evidence from User Perceptions}

Daoudi (2011) examines electronic Arabic used over the Internet and in mobile phones and studies the implications of globalization on the development of both standard Arabic and spoken dialects. Her data is collected using an Internet based corpus consisting of 150 million words, semi-structured interviews and observations in Arab countries. The findings show that there are borrowings from other languages into Arabic both at the literal and figurative levels. Some of these loan words are adapted to suit pronunciation and spelling in addition to the morphology of the absorbing language, i.e., Arabic. Furthermore, the researcher notes the substitution of Arabic letters which have no English/French equivalent with numerals and Romanized Arabic. This, she argues, has a role in the rise of colloquial Arabic in SMS and the Internet. Additionally, she adds that the use of such features as numerals and Roman alphabet liberated a large section of the population, especially those who do not possess well command of Modern Standard Arabic (MSA) and gave them a wider access to all sorts of communication

In another closely related study, Hamdan (2012) examines the linguistic and textual features of Arabic CMC. His study relies on a large corpus of authentic public web chat sessions taken from the Kalamngy Jordan chat room [www.kalamngy.com] and private instant messages taken from Windows Live Messenger. The findings of the study show that cyber Arabic is characterized by a number of linguistic features such as the significant use of short sentences and contracted forms, in addition to the widespread use of taboo words, typos, unconventional spelling and punctuation, mix of scripts, mix of letters with numbers and symbols, and the use of emoticons. Further, the study reports that there seems to be a tendency among website and program developers towards making communications seem more speech-like. The researcher cites the introduction of the 'seen' feature in messenger by Facebook as an example of that as it enables a Facebook user to know who of his/her friends saw the message that was sent. In Hamdan's (2012, 147) words:

This 'seen' feature is like a confirmation from Facebook that user y, for instance, has received and read the message sent by user $\mathrm{x}$. This would in no way give user $\mathrm{y}$ a chance to say that he/she did not see the message or that he/she did not respond back because the Internet, say was disconnected or the message was not received.

In a recent study, Hamdan and Al-Salman (2021) examine the use of Arabic neologisms in social media applications. The researchers report that the "use of neologisms is attributed to reasons of practicality and convenience, accuracy and relevance, trendiness and internationalization, in addition to lack of equivalence in the Arabic language system" (Hamdan and Al-Salman, 2021:45).

As is clear, none of these studies addressed nonverbal e-communication whether in the Arab/ Jordanian context or elsewhere, thus allowing some room for studies like the one reported here to step in and promote current research on CMC. 
Hamdan

\section{Nonverbal Communication and Emojis in CMC}

A language is a system of symbols through which people communicate. These symbols may be spoken, written, or signed with the hands (Kreidler 1998, 19). With the introduction of the Internet, the advent of social media networks, and the penetration of thousands of applications, language users started to develop new forms of language in a variety of ways in order to compensate for the lack of nonverbal cues available in face-to-face interactions. To this end, emojis were introduced. According to Cambridge dictionary, an emoji is "a digital image that is added to a message in electronic communication in order to express a particular idea or feeling." Before the rise of emojis in the late 1999s, emoticons - facial expressions that are made through the use of punctuation marks like ' $\left({ }^{\wedge} \_\wedge\right)$ - were first used, representing an important aspect of early netspeak. According to Nowak (n.d.) from the Reader's Digest website, "when it became difficult for people to tell the difference between jokes and serious posts on a Carnegie Mellon University digital message board, faculty member Scott Fahlman came up with a solution: Add the symbol :-) to denote humorous posts, and add the symbol :-( to serious ones." Thus, internet users started to resort to these primitive gestures to convey different states of mind and feelings. Emojis were introduced later in 1999 in Japan by Shigetaka Kurita who created them for the phone company he worked for, NTT Docomo, in order to make it easier for the customers to communicate their emotions through icons in an attractive and simple way. Thus, instead of typing the word 'cloudy', all one needs to do is to press the 12- by 12-pixel image or icon to show the weather forecast. With time, other companies followed suit and started to introduce their own emojis. Then, emojis became pervasive and available to everyone as a lingua franca or actually as a new digital language that connects people. In a CMC conversation, a message like 'I understand' as such may sound cold and passive, but if a user opts for a

folded hands emoji 1 or a heart emoji the same message offers more warmth and sympathy. Emojis are not just random pictures; rather, they are more of a new universal language that is bringing together and connecting Netizens from all around the world in the digital age.

Although emojis are pervasive, it is important to analyze their pragmatic functions as they do and can create misunderstandings sometimes, since some emojis may be interpreted differently because of cultural or contextual differences. An emoji is just like any utterance, verbal or otherwise. In order to interpret the meanings of an emoji in a written discourse, one needs to be reasonably aware of its physical context, that is the time and the medium or channel in which it is used, the people involved in the interaction, their backgrounds, their relationships to one and another and what they know about one another (Kreidler,1998, p. 25). Austin (1962) argued that words can do actions; they convey different illocutionary forces. Likewise, an emoji can convey multiple illocutionary forces depending on its

physical-context. For example, in the Jordanian context, while the emoji of the like button is used to convey appreciation in some circumstances, it is, as will be shown in section 7, used to convey other functions including showing unreserved approval, admiration of content, and showing mockery, among others.

In light of this presentation, defining and identifying the pragmatic functions of emojis is of paramount importance to promote mutual understanding among social media interlocutors. Further, this 
The Pragmatic Functions of Facebook Likes on Status Updates:

Evidence from User Perceptions

helps social network developers match the expectations of language users who keep shaping and reshaping the digital language with a view to making it more responsive to their growing needs. Finally, it is hoped that this study will contribute to bridging this gap by exploring the pragmatic functions of the like button on Facebook.

\section{Facebook and the Like Emoji Button}

\subsection{Overview}

Facebook is a social network founded by Mark Zuckerbeg in 2004. Initially, it was called The Facebook, and its membership was limited to Harvard students, but the company later in 2005 dropped 'the' from its name and expanded the site's membership gradually to other colleges and universities across the United States and Canada until it became in 2006 open to everyone aged 13 and above with a valid email address. On the website, users can create a profile, add their personal information, share pictures of themselves and interact through posts, stories, messages and comments with people they know or with people they do not know. Participants added to one's profile are called 'friends'.

Friends on Facebook can contact each other in an asynchronous (delayed) manner through comments and likes, and can interact with one another in a synchronous (real-time communication) manner through the messenger application. Due to its hybrid nature and complexity, it is not always easy to pinpoint when a communication is synchronous and when it is asynchronous. For example, while commenting on one's status, the communication is supposed to be asynchronous, but it may not. There are instances when people write a comment on a status, seconds after it is published.

People use Facebook to express their feelings, beliefs, and points of view. Each Facebook user has a wall and it is on this wall that a user can share anything on their mind by writing a status, also called a post. A user can adjust privacy settings so as to have the post shared with all friends, specific friends, and the public, including those not in the friends' list.

\subsection{Introducing the Like Button}

When Facebook was first launched, users did not have multiple options to react to a status. The only option available was writing a comment. It is only on February 9, 2009 that Facebook introduced a new feature, the like feature to enable users to like status updates, photos, videos, and links shared by friends. On Facebook's official page, the like feature is described as "a way to let people know that you enjoy it [a post] without leaving a comment." Since liking and commenting were the most common features, Facebook officials decided in 2010 to extend the like button to comments. In the words of Whitnah (2010). One of Facebook's software engineers:

So like peanut butter and jelly, we realized these two features [liking and commenting] would go better together. Starting today, most of you will see a small "Like" button appear underneath comments... Whether it's a witty remark, a great point in a discussion or a helpful answer to someone's question, clicking the "Like" 
Hamdan

button within comments now makes it simple to show your appreciation for all types of content on Facebook.

After years of questions by the public on whether Facebook is willing to introduce a 'dislike' button, Facebook officially rolled out a feature called 'Reactions' in 2016 to let users express five different emotions in addition to the like including 'love', 'haha', 'wow', 'sad' or 'angry'. To activate these emotions, a user must long-press on the like button and choose one of these five pre-defined emotions. This ability to use these emotions was then extended to comments in 2017. All that a Facebook user needs to do to activate these emotions is to long-press on the like button under a comment to react to it.

Now that the readers have hopefully had a better understanding of how the Facebook 'like' feature works, it is expedient to highlight that this paper examines the pragmatic functions of likes on statusupdates not likes on comments, pictures or likes sent in messages. Whenever a Facebook user writes a status, any of his/her friends can like that status if they simply press on the word 'like' written under that status or if they long-press it and choose the like emoji from the suggested reactions.

\section{Pragmatics and Discourse Markers}

The chief concern of pragmatics is to study "a person's ability to derive meanings from specific kinds of speech situations - to recognize what the speaker is referring to, to relate new information to what has gone before, to interpret what is said from background knowledge about the speaker and the topic of discourse, and to infer or 'fill in' information that the speaker takes for granted and doesn't bother to say" (Kreidler, 1998, 19). The same utterance said by a speaker to a listener could have multiple interpretations depending on the context. For example, 'the place is closing' when uttered by a speaker, could be a simple statement, a warning for the costumers to hurry and get the final purchase, an invitation or a command to leave (Saeed, 2003, 17). In fact, it could even have more meanings depending on the speaker's intention, the context and the setting.

Due to the growing interest in spoken language and verbal communication, one phenomenon which has attracted extensive pragmatic investigation among linguists is 'discourse markers' (Fraser, 1990). According to Fraser (1990, p. 387), discourse markers fall under the umbrella of pragmatic markers and are "a class of lexical expressions that signal a relationship between the interpretation of the segment they introduce, S2, and the prior segment, S1." Examples of discourse markers include 'however, furthermore' so' etc.

In one of the earliest studies to examine the pragmatic functions of discourse markers in Arabic, Farghal (1995) investigates the pragmatic functions of ?insha:?allah 'God willing'. The findings show

that this discourse marker "drifted extensively from its semantic import by acquiring a wide spectrum of illocutions, thus becoming a pragmatically multi-purpose expression. In another study, Kanakri \& AlHarahsheh (2013) study the pragmatic functions of the discourse marker Ga:di 'normal'. They report that this expression is used to express consolation, to ask for permission, to express disapproval, to show disappointment, and finally to save one's face, among others.

In a recent study, Hamdan and Abu Rumman (2020) investigate the pragmatic functions of Yahummalali in Jordanian spoken Arabic. The researchers report that this discourse marker has nineteen 
The Pragmatic Functions of Facebook Likes on Status Updates:

Evidence from User Perceptions

pragmatic functions, e.g. expressing dismay and disapproval, fear, condemnation, disappointment, mitigating exaggerated claims, wishing, expressing sadness, etc.

As is clear, whilst several pragmatic markers, particularly discourse markers, received thorough scholarly attention in Arabic, not a single study, to the best of the researcher's knowledge, has examined the pragmatic functions of CMC nonverbal pragmatic markers, particularly the like button in statusupdate likes on Facebook.

\section{Methodology}

Since this study investigates the pragmatic functions of the like button with a view to unveiling the context, i.e. situation, circumstances and setting, in which it is used or the reasons that motivate such usage, the researcher thought that the best procedure is to approach users themselves directly to provide relevant data. Thus, he asked a friend who happened to be a university professor to write a status update on his Facebook account in which he requested his Facebook friends (including students, colleagues, etc.) to report to him in a comment when each of them tends to press the like button on a status and for what purpose. This method was found useful because the researcher elicited the data through perceptions of the users. There is no other explicit and straightforward way for the observer to figure out the function of pressing the like button on status updates as intended by the user but through directly approaching the user and eliciting his/her response to a direct question on why he/she employs the like button. The total number of the collected comments is 218 . The researcher examined them carefully in order to identify the pragmatic function of the like button reported in each comment. Analysis of data revealed that 8 pragmatic functions were evident. Next, the researcher calculated the number of tokens under each function to measure the frequency and percentage of each pragmatic function.

\section{Results and Discussion}

The advent of the Internet, the rise of social media networks and the penetration of huge amounts of applications into our daily life have changed the ways we used to communicate with each other through language. Not only were software developers unlikely to expect the drastic changes, but they were not always able to cope with them. To illustrate, let us take the like button as an example. When it was first introduced by Facebook in 2009, the purpose as described on the website's page was to "let people know that [users] enjoy [a post] without leaving a comment”. In the Jordanian context, however, analysis of data shows that the actual use of the like button has gone beyond this function. While the purpose of promoting appreciation is met by some users, the button is used by others to convey a whole host of other feelings and functions including ridiculing others which contradicts the whole jest behind the introduction of the like button by Facebook. Table 1 provides the percentages of the pragmatic functions that underlie the use of the like button. 
Hamdan

Table 1: Percentages of the Pragmatic Functions of the Like Button

\begin{tabular}{clc}
\hline No. & \multicolumn{1}{c}{ Function } & \% \\
\hline 1 & Showing unreserved approval and admiration & 33 \\
2 & Showing courtesy and maintaining contact & 21.8 \\
3 & Notifying user that the post has been seen and followed & 18.2 \\
4 & Indicating reserved approval if a written comment may invite problems & 14 \\
5 & Showing flattering and apple polishing to the user & 6.10 \\
6 & Notifying and inviting friends to see a public post & 2.6 \\
7 & Ensuring receipt of notification of comments and reactions to the post & 2.6 \\
8 & Showing mockery of published content & 1.7 \\
\hline
\end{tabular}

A glance at this table reveals that this button is used to convey 8 pragmatic functions in total, ranging in purpose from showing unreserved approval and admiration of content, the most frequent function $(33 \%)$ to showing mockery, the least frequent one $(1.7 \%)$.

As can be seen from table 1 , the like button was used to convey 8 pragmatic functions that vary in weight. While the first five ranged in frequency between 6.10 per cent and 33 per cent, the remaining five ranged between 1.7 per cent and 2.6 per cent. Below is a brief account of each function along with illustrative examples extracted from the corpus. For the readers' convenience, examples from the subjects' responses will be presented at two levels: (1) Arabic script and (2) English glossing.

\subsection{Showing Unreserved Approval and Admiration}

This function was reported by about one third of subjects (33\%). Here, the Facebook (FB) respondent presses the like to show his/her unreserved approval and admiration of the post. The respondent likes the shared content regardless whether s/he knows the poster or not. This is in line with the original function suggested by FB for using the like button.

$$
\text { (1) أضع اللايك إذا كان المحتوى يعجبني، سواء كنت أعرف صاحب المنشور أو لا. }
$$

'I press the like if I like the content, whether I know the author of the post or not.'

Here, a like is simply just like a pat on the back, acting as a positive face enhancer — using Brown and Levinson's (1987) terms, that enhances an interlocutor's self-image.

\subsection{Showing Courtesy and Maintaining Contact}

In its attempt to offer more options for users to express themselves effectively and to match their expectations and their growing needs, Facebook introduced the 'reactions' feature to allow users to choose from five different emotions including 'love', 'haha', 'wow', 'sad' or 'angry' when reacting to a status. However, while these five are among the most commonly expressed emotions in real life, none can express the function of courtesy, which is an indispensable requisite for maintaining friendship and social bonds. Here, pressing a like is just like saying 'hello, how are you'. It is what Kreidler (1998, p. 194) calls a 'phatic utterance' that is used to "establish rapport between members of the same society." Thus, due to the need in real life to maintain contact and show courtesy between friends, Facebook users extended the 
The Pragmatic Functions of Facebook Likes on Status Updates:

Evidence from User Perceptions

functions of the like button to include this when they simply press the like just to stay in touch with their friends and probably as a way of saying, though implicitly, 'I am checking on you'.

The like here serves as a lubricant of human relationships.

$$
\text { أستخدم الاعجاب كنوع من المجاملة للشخص والاهتمام به. }
$$

'I use the like button to show courtesy to a poster.'

Sometimes and especially in cases of disagreements, users press the like button to show respect of another user's perspective. Here,the FB respondent opts for a like even when the status content goes against his/her beliefs or values in an attempt to show courtesy, tolerance and mutual respect of disagreement or difference.

$$
\text { (3) ربما لا اقتتع بفكرة المنشور او لست معها ولكن اضع لايك كأسلوب للمجاملة وللتعبير عن احترام رأي الناشر. }
$$

'I may not be sharing the poster's same beliefs and perspectives but I press a like as a way to show courtesy and respect to the poster's view.'

\subsection{Notifying User that the Post has been Seen and Followed}

To convey this function, the FB respondent presses the like button to send a message to the posters that their status has been seen and that there is an interest in seeing future posts.

$$
\text { (4) في الفالب نعمل لايك فقط لإيصال معلومة للناشر أننا رأينا وقرأنا المنشود . }
$$

'We usually press a like to send a message to the poster that his or her post has been seen and read.'

\subsection{Indicating Reserved Approval if a Written Comment may Invite Problems}

Here, the FB users opt for a like instead of writing a comment when they have reservations on the post which they do not feel they can share publicly or when writing a comment may invite problems or place the respondent in a socially embarrassing situation. For instance, if the FB user does not know the background of the poster's friends, he/she may hesitate to write a comment that shows an opposing view as this may lead to quarrels and clashes with some commentators. Further, some users opt for a like as a way to avoid possibly embarrassing situations. A male user, for instance, reported that he used to press a like instead of writing a comment under a status posted by a female to show interest in contexts where a comment maybe socially embarrassing. Suppose a Jordanian female poster has a picture of herself in the status and a male compatriot writes her a flattering comment. Some of his or her friends may question his comment or their relationship and this may place one of them or both in an embarrassing situation. A mere like is viewed as a safe option in this case.

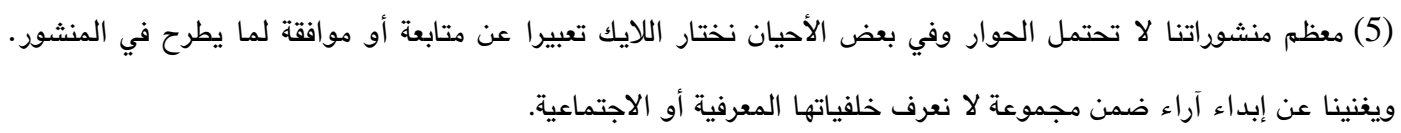

'Most of our posts do not allow for dialogue and thus we sometimes opt for a like to indicate that we follow a post and like it instead of sharing a written view with commentators whose social and cognitive backgrounds are hardly known to us.' 


$$
\begin{aligned}
& \text { Hamdan } \\
& \text { (6) بالنسبة لي لايك بدون تعليق تعني يعجبني لكن تعليقي قد يجر جدلاً مع من يتحفظون عليه. }
\end{aligned}
$$

'For me a like with no comment means approval, but my comment may lead to arguments with those who have reservations on my comment.'

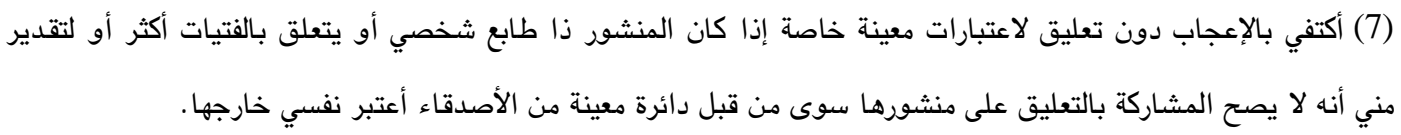

'I go for a like with no comment for special considerations, particularly if the post has a personal nature or has to do with girls more than males or in cases when I feel that comments under it are only possible by a small circle of friends of which I am not a member.'

Further, some respondents stated that they opt for a like when a status they are following addresses a delicate topic like politics and religion, among other sensitive issues. They added that in such a context they feel they are unable to post a textual comment which may cause unnecessary troubles to them.

$$
\text { (8) أضع اللايك لعدة أسباب منها... إذا كان الموضوع حساس مثل السياسة وفعليا لا أستطيع التعليق عليه. }
$$

'I press a like for multiple reasons... a case in point is when the topic is highly sensitive like politics and I actually cannot leave a comment about it.'

Being direct or critical in politics, especially in countries where cybercrime laws are enforced may intimidate some Facebook users as they may be held accountable of what they say or write. Such a context may put off users from engaging in written comments when such sensitive topics are discussed. Thus, a user may opt for being indirect instead of being elaborative in order to avoid getting into trouble.

\subsection{Showing Flattering and Apple Polishing to the User}

Here, as the label implies, the FB respondent opts for a like to flatter or apple polish the poster who could possibly be his/her friend, supervisor, boss or someone of importance even if the shared content is not viewed favorably by the respondent. While the act of apple polishing may be spotted and recognized by the recipient in face-to-face verbal communication, the case is unlikely to be so in this very particular context of CMC. At best, the recipient may view this like favorably, probably as a sign of appreciation or as an indication of a desire to maintain contact; at worst the like may pass unnoticed and thus it does not cause any harm to the user.

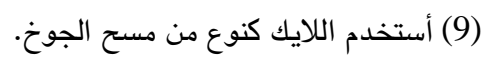

'I use the like button as a form of apple polishing.'

\subsection{Notifying and Inviting Friends to See a Public Post}

Here the FB respondent presses a like on a public post to notify his/her friends of the post and to indirectly invite them to see its content. When a Facebook user navigates the home screen of his/her profile, posts liked and commented on by his/her friends will usually be displayed.

$$
\text { (10) هو اللايك الهدف منه الاشارة الى المنشور حيث يظهر لدى أصدقاء صاحب اللايك. }
$$

'The purpose behind a like is to notify my friends about a post so that it becomes accessible to them.' 
The Pragmatic Functions of Facebook Likes on Status Updates:

Evidence from User Perceptions

One possible motivation of this like is the respondent's desire to use the content of the post to support or refute a point that was raised in a previous conversation with a friend. Another possible motivation is the respondent's intention to encourage, though indirectly, some of his/her FB friends to view the post and respond to it.

While this function was reported by older respondents, the researcher observes that younger Facebook users tend to use 'tagging' instead of liking a public status in order to mention their friends, make the status more visible to them and invite them for discussion. Simply, they comment on a status and tag their friends in the body of the comment. A tagged user then once notified by Facebook can either take part in the discussion, react to the status, ignore the tag or even untag themselves.

\subsection{Ensuring Receipt of Notification of Comments and Reactions to the Post}

Here, the respondent presses the like button in order to be able to follow reactions to it in terms of who likes it and what comments it attracts. Once a user presses a like on a status, he/she will automatically receive a notification from Facebook whenever any other users comment on the status he/she is following. This is also an emerging pragmatic function that is worthy of more inspection and exploration in future research.

$$
\text { (11) أحيانا اضع اللايك لاتابع التعليقات على المنشور فتصلني اشعاراته. }
$$

'Sometimes, I press the like to be notified of comments written in response to the status in question.'

\subsection{Showing Mockery of Published Content}

Although the general purpose of the like is to show appreciation, some respondents suggested an interesting yet unexpected function in which they sometimes pressed the like button to indicate that the content being shared is nonsense or worthless. It is as if by pressing a like they are telling the poster indirectly that his/her posts are not worth a comment and that they are rubbish.

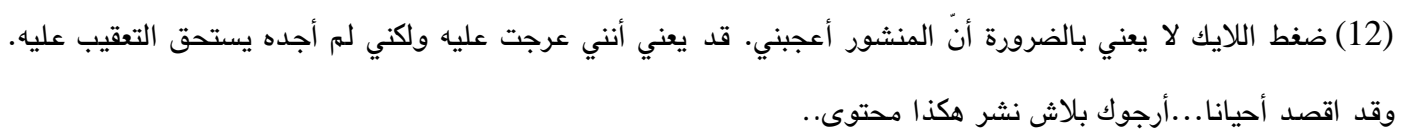

'Pressing a like doesn't always imply approval of the post. It may mean that I saw its content but I didn't find it worth commenting on. I may also intend in some cases to tell the poster to stop posting such meaningless content.'

\section{Conclusions and Recommendations}

The findings of this study revealed that in the Jordanian context, the like button, the equivalent of the emblematic 'thumbs up' real-time hand gesture is not solely used to show appreciation and that it has emerged primarily as a CMC graphic pragmatic marker with eight pragmatic functions. The like button may be used for instance to notify a user that a post is seen and followed. It could further be used to indicate a reserved approval if a written comment may invite problems. Sometimes, a like is used to show flattering and apple polishing, especially when pressed on posts written by those higher in power such as 
Hamdan

managers and directors. A like may as well be pressed by some to indirectly invite friends to see a post, especially if it is public. Some users may even press the like on a post to ensure receipt of notifications of comments. Finally, a like may not always have positive motives. Sometimes, a user may press a like to show mockery of published content.

Exploring the pragmatic functions of the like button is extremely important as unawareness or unfamiliarity with the multiple functions that this button does have may cause trouble. A like may not be solely used just to indicate approval. For example, when a Facebook user presses a like on a post that announces the death of someone, the user does not press the like button to show excitement about others' pain or misery but to notify his/her FB friend that the post has been seen and followed.

Since the use of this pragmatic marker is not restricted only to Jordanians, as it is used worldwide, future research may examine its pragmatic functions among netizens from other regions to see whether its pragmatic functions are cultural-specific or show a tendency towards universality. Further, to address the limited generalizability of the findings of the study, future research may elicit similar data from a larger number of subjects from different genders, age groups and social status.

Another variable which was not examined in this study which could yield interesting results is the power variable. The role of power in terms of equal and/or different status between the professor who directed the post and the respondents cannot be overlooked as some of them were his students, i.e. of lower status. This might have affected the number and content of responses that were analyzed to derive the functions of the like button.

Finally, due to the scarcity of studies that examine nonverbal communication in CMC, particularly emojis, it is recommended that future research examine the pragmatic functions of the most used emojis on social media networks like Facebook and Twitter, especially in the Arab/ Jordanian context, to find out when do users press them and for what purposes. 
The Pragmatic Functions of Facebook Likes on Status Updates:

Evidence from User Perceptions

$$
\begin{aligned}
& \text { الوظائف البراغماتية لزر الإعجاب على المنشورات الفيسبوكية من } \\
& \text { وجهة نظر المستخدم } \\
& \text { هادي حمدان } \\
& \text { قسم اللفة الإنجليزية وآدابها، الجامعة الأردنية، الأردن }
\end{aligned}
$$

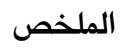

تهدف هذه الدراسة إلى تحليل الوظائف البراغماتية لزر الإعجاب في المنشورات الفيسبوكية عند مستخدمي هذه المنصة

الاجتماعية. ويهدف جمع البيانات، طلب الباحث من صديق له يعمل أستاذاً جامعياً أن يكتب منثوراً على صفحته الثخصية

يطلب فيه من طلبته وزملائه وأصدقائه أن يخبروه بالسياقات التي يستخدمون فيها هذا الزر والوظائف اللفوية له عن طريق

كتابة تعليق. وقد بلغ عدد التعليقات التي جمعت وحللت 218 تعليقاً. وأظهرت نتائج تحليل البيانات أن استخدامات زر

الإعجاب في المجتمع الأردني لا تقتصر على التعبير عن الإعجاب فقط كما أراد مطورو الفيسبوك لهذا الزر ولكن تتعداها

لتشمل ثماني وظائف لغوية أخرى تتراوح بين إظهار القبول والإعجاب وتصل إلى حد التهكم على المحتوى المنشور.

الكلمات المفتاحية: التواصل بالحاسوب على الإنترنت، الإيماءات، الإيموجي، اللايك، الوظائف البراغماتية. 
Hamdan

\section{References}

Al-Sa'di, Rami, and Jihad Hamdan. 2005. Synchronous Online Chat English: Computer-mediated Communication. World Englishes 24 (4): 409-424.

Austin, John. 1962. How to Do Things with Words. Oxford: Clarendon Press.

Banikalef, Ala'eddin. 2019. The Impact of Culture and Gender on the Production of Online Speech Acts among Jordanian Facebook Users. International Journal of Arabic-English Studies (IJAES) 19 (2): 399-414.

Brown, Penelope and Stephen Levinson. 1987. Politeness: Some Universals in Language Usage. Cambridge: Cambridge University Press.

Cambridge Dictionary, s.v. “emoji”. https://dictionary.cambridge.org/ dictionary/english/emoji (accessed February 13, 2020).

Crystal, David. 2001. Language and the Internet. Cambridge: Cambridge University Press.

Daoudi, Anissa. 2011. Globalisation and E-Arabic: The Emergence of a New Language at the Literal and Figurative Levels. In Language contact in times of globalization (Studies of Slavic and general linguistics) eds. Peter Houtzagers, Janneke Kalsbeek and Jos Schaeken, 61-71. Amesterdam - New York: Rodobi.

Denis, Derek. 2008. Linguistic Ruin? Lol! Instant Messaging and Teen Language. American Speech 83: 3-34.

Dressler, Roswita and Anja Dressler. 2016. Linguistic Identity Positioning in Facebook Posts During Second Language Study Abroad: One Teen's Language Use, Experience, and Awareness. The Canadian Journal of Applied Linguistics 19 (2): 22-43.

Farghal, Mohammed. 1995. The Pragmatics of 'inšāllah in Jordanian Arabic. Multilingua - Journal of Cross-Cultural and Interlanguage Communication 14 (3): 253-270.

Fraser, Bruce. 1990. An approach to Discourse Markers. Journal of Pragmatics 14 (3): 383-395.

Fraser, Bruce. 1999. What Are Discourse Markers? Journal of Pragmatics 31: 931-952.

Grice, Paul. 1975. Logic and Conversation. In Syntax and semantics, eds. Peter Cole and Jerry Morgan, 41-102. New York: Academic Press.

Halim, Nur and Marlyna Maros. 2014. The Functions of Code-switching in Facebook Interactions. Procedia - Social and Behavioral Sciences 118: 126-133.

Hamdan, H. J. 2012. The linguistic and textual features of synchronous online chat-Arabic: Computermediated communication. MA Thesis, University of Jordan.

Hamdan, Hady J. and Saleh Al-Salman. 2021. The Use of Arabic Neologisms in Social Media Applications. International Journal of Arabic-English Studies (IJAES) 21 (1): 45-60.

Hamdan, Jihad and Ronza Abu Rumman. 2020. The Pragmatic Functions of Yahummalali in Jordanian Spoken Arabic. Jordan Journal of Modern Languages and Literatures 12 (3): 327-345.

Kanakri, Mahmoud and Ahmad Al-Harahsheh. 2013. The Discourse Analysis and Pragmatics of Pa:di in Jordanian Spoken Arabic. International Journal of English Linguistics 3 (6): 59-63. 
The Pragmatic Functions of Facebook Likes on Status Updates:

Evidence from User Perceptions

Kreidler, Charles. 1998. Introducing English Semantics. London: Routledge.

Magwaro, Gideon., Elizabeth Odhiambo and Silas Owala. 2018. An Analysis of the Linguistic Features

Used in Selected Social Interactions on Facebook. Education and Linguistics Research 4 (1): 35-44.

Nowak, Claire. 2016.. Why do we use emojis anyway? A fascinating history of emoticons. https://www.rd.com/culture/history-of-emoji/ (accessed 12 January, 2020).

Noyes, Dan. 2020. The top 20 valuable Facebook statistics - Updated January 2020. https://zephoria.com/top-15-valuable-facebook-statistics/(accessed 10 February, 2020)

Palfreyman, David and Muhamed Al-Khalil. 2003. A Funky Language for Teenzz to Use: Representing Gulf Arabic in Instant Messaging. Journal of Computer-mediated Communication 9 (1).

Perez-Sabater, Carmen. 2012. The Linguistics of Social Networking: A Study of Writing Conventions on Facebook. Linguistik Online 56 (6): 81-93.

Saeed, John. 2003. Semantics. Oxford: Blackwell Publishers.

Segerstad, Ylva. 2002. Use and adaptation of written language to the conditions of computer-mediated communication. $\mathrm{PhD}$ dissertation, Goteborg University, Sweden.

Stevenson, Abigail. 2016. Cramer Remix: Facebook isn't just technology anymore. https://www.cnbc.com/2016/07/28/cramer-remix-facebook-isnt-just-technology-anymore.html (accessed 10 January, 2020)

Whitnah, Tom. (2010). I like your comment. https://www.facebook.com/notes/facebook/i-like-yourcomment/399440987130/ ( accessed 15 May, 2020) 